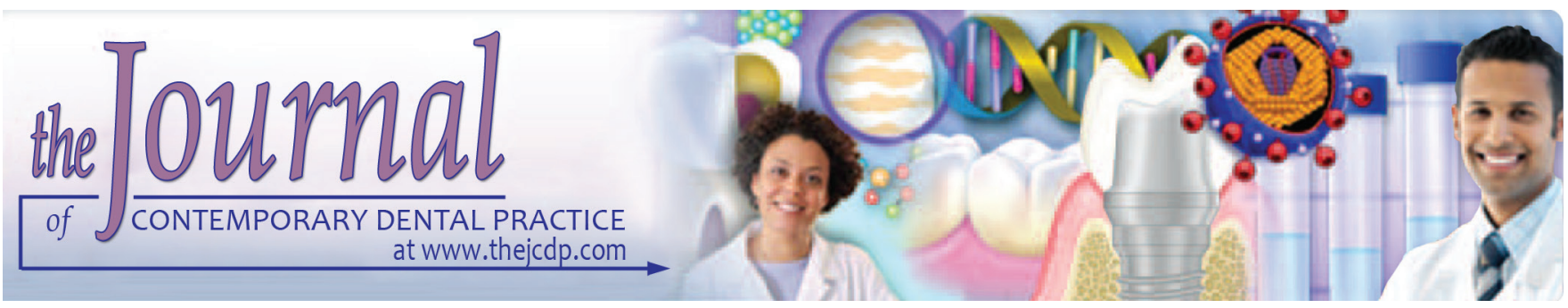

\title{
Evaluation of Influence of Widening Apical Preparation of Root Canals on Efficiency of Ethylenediaminetetraacetic Acid Agitation Protocols: Study by Scanning Electron Microscopy
}

\author{
${ }^{1}$ Ana CL Marques, ${ }^{2}$ Bernardo A Aguiar, ${ }^{3}$ Luciana MA Frota, ${ }^{4}$ Bruno M Guimarães, ${ }^{5}$ Nilton Vivacqua-Gomes \\ ${ }^{6}$ Rodrigo R Vivan, ${ }^{7}$ Marco AH Duarte, ${ }^{8}$ Bruno C de Vasconcelos
}

\begin{abstract}
Aim: The purpose of this study was to evaluate the influence of widening the apical root canal preparation (RCP) on the efficiency of different ethylenediaminetetraacetic acid (EDTA) agitation protocols on smear layer removal: EDTA; EDTA + Easy Clean in rotary movement (ECROT); EDTA + Easy Clean in reciprocating movement (ECREC); and EDTA + Passive ultrasonic irrigation (PUI).
\end{abstract}

Materials and methods: A total of 80 mandibular premolars had their crowns sectioned and then were divided into two groups according to widening: size 25 or $40,0.08$ taper. Sequentially they were once again allocated to subgroups according to the agitation protocol performing eight experimental groups $(n=10)$. Ten additional teeth were prepared for controls $(\mathrm{C}+/ \mathrm{C}-)$. The specimens were then submitted to the cleaning protocols and thereafter cleaved and microphotographed by variable pressure scanning electron microscopy (SEM) at previously determined

\footnotetext{
${ }^{1}$ Private Practice, Fortaleza, Ceará, Brazil

${ }^{2,3}$ Post-Graduate Program in Dentistry, School of Pharmacy Dentistry and Nursing, Federal University of Ceará, Fortaleza Ceará, Brazil

4,6,7 Department of Dentistry, Endodontics and Dental Materials Bauru Dental School, University of São Paulo, Bauru, São Paulo, Brazil

${ }^{5}$ School of Dentistry of Ceará, São Leopoldo Mandic University Fortaleza, Ceará, Brazil

${ }^{8}$ Post-Graduate Program in Dentistry, School of Pharmacy Dentistry and Nursing, Federal University of Ceará, Fortaleza Ceará, Brazil; School of Dentistry of Sobral, Federal University of Ceará, Sobral, Ceará, Brazil

Corresponding Author: Bruno C de Vasconcelos, PostGraduate Program in Dentistry, School of Pharmacy Dentistry and Nursing, Federal University of Ceará, Fortaleza, Ceará Brazil; School of Dentistry of Sobral, Federal University of Ceará Sobral, Ceará, Brazil, Phone: +5536132603, e-mail: bcv@ufc.br
}

points along their root thirds $(750 \times)$. Scores were attributed to the images, and data were analyzed by the Kruskal-Wallis, Student-Newman-Keuls and Friedman tests.

Results: A higher widening was observed to have a positive influence on cleaning efficiency offering significant differences in global and apical third evaluations $(p<0.05)$. Relative to the agitation, significant differences were observed mainly in the apical third, with PUI and ECROT providing the best results $(p<0.05)$; no difference for $C+$ was observed when higher widening was employed.

Conclusion: A greater widening of the apical third provided a significant improvement in the action of the agitation/activation protocols. Moreover, the PUI and ECROT activation methods were shown to be superior to the use of EDTA solely, particularly in the apical third.

Clinical significance: The findings of this study reinforce the need for clinical use of additional methods to complement cleaning. Therefore, it is important for professionals to have knowledge and command of these protocols to obtain more satisfactory results.

Keywords: Easy clean, Endodontics, Ethylenediaminetetraacetic acid, Laboratory research, Passive ultrasonic irrigation, Scanning electron microscopy evaluation.

How to cite this article: Marques $A C L$, Aguiar $B A$, Frota LMA, Guimarães BM, Vivacqua-Gomes N, Vivan RR, Duarte MAH, de Vasconcelos BC. Evaluation of Influence of Widening Apical Preparation of Root Canals on Efficiency of Ethylenediaminetetraacetic Acid Agitation Protocols: Study by Scanning Electron Microscopy. J Contemp Dent Pract 2018;19(9):1087-1094.

Source of support: This work was partially supported by Research Support Foundation of São Paulo State (FAPESP 2016/00245-1).

Conflict of interest: The authors deny any conflict of interests associated with this study. 


\section{INTRODUCTION}

The purpose of endodontic therapy is to eliminate as much as possible microorganisms and debris from the root canal system (RCS) through chemical-mechanical preparation. ${ }^{1}$ However, in the literature, it has been clearly pointed out that the action of endodontic instruments is incapable of touching all the canal walls to promote complete cleaning of the RCS. ${ }^{1}$ Therefore, irrigation plays an indispensable role in cleaning inaccessible areas or those untouched during instrumentation. ${ }^{2}$

Another problem commonly found during RCP is smear layer formation by the action of endodontic instruments. This is an amorphous residual layer constituted of organic tissues, such as pulp remainders and bacteria, and inorganic matter, such as dentin scrapings. ${ }^{3}$ This layer obstructs the dentinal tubules, harming their decontamination by means of the irrigant solution, besides impairing the adaptation of the filling material with the walls of the canal, promoting the infiltration of fluids inside the canal and making the removal of the smear layer a factor important for a better action of irrigation solutions in the disinfection of RCP. ${ }^{4}$

The substance most commonly used for RCS irrigation is sodium hypochlorite solution $(\mathrm{NaOCl}) .{ }^{2}$ But their cleaning action is limited, ${ }^{5}$ which is complemented by the action of EDTA, a chelating agent with the capacity for decalcifying and removing calcium ions from dentin and the smear layer, acting on their inorganic portion and thus promoting the opening of the dentinal tubules. ${ }^{5}$ Another crucial factor for smear layer removal is the volume of irrigant used, since the reflux created during the irrigation and aspiration procedures promote greater debris removal. ${ }^{6}$

The simplification of instrumentation during RCP procedures resulted in a shorter time of action of the irrigant solution, influencing cleaning of the RCS, particularly in the apical third. ${ }^{7,8}$ Because this third has a complex anatomy, is distant from the canal opening and due to the formation of air bubbles (apical vapor lock), it ends up receiving a smaller volume of irrigant solution. ${ }^{9,10}$ Also related to this simplification, where decontamination is concerned, recent results have pointed out greater microbial reduction when larger apical widening has been performed. ${ }^{11}$ As a manner to achieve this cleaning, various additional protocols have appeared with the intention of compensating the shorter time of action of the irrigant solution. In this sense, PUI, in which an ultrasonic insert is used to promote ultrasonic cavitation action, acoustic microevaporation, and waves of impact on the irrigant solution, with the purpose of increasing smear layer, debris, and biofilm removal. According to the literature, PUI offered the best results relative to cleaning and debris removal. ${ }^{12,13}$
Easy Clean (EC; Easy Dental Equipment, Belo Horizonte, MG, Brazil), recently launched in the USA, is a plastic instrument size 25, 0.04 taper, with a flat crosssection, indicated by the manufacturer for use in reciprocating movement. ${ }^{14}$ It has been characterized as the most accessible and simple option for the use of PUI, which may represent a universalizing option to use for agitating irrigation solutions. Up to now, there are only two studies available in the literature, which have evaluated EC points, and both raised very encouraging perspectives. ${ }^{14,15}$

Considering the importance of using additional protocols as a way of increasing disinfections and cleaning of root canals, the authors understood that it was relevant to evaluate the influence of widening apical preparation on the efficiency of different EDTA agitation protocols in the final cleaning of root canals, by evaluating the use of EDTA alone, and the protocols of agitating it with PUI, EC in rotary movement, and EC in reciprocating movement. The null hypothesis considered was that there would be no differences in the efficiency of cleaning achieved by the final cleaning protocols, irrespective of the apical widening performed.

\section{MATERIALS AND METHODS}

After approval by the Research Ethics Committee (Protocol \#615854), 90 unirradicular human mandibular premolars classified as ${ }^{1} \mathrm{TN}^{116}$ extracted for reasons other than the research were collected for the study. The crowns were sectioned with the purpose of allowing the roots to be standardized to a length of $15 \mathrm{~mm}$, checked by means of a digital pachymeter with precision of $\pm 0.001 \mathrm{~mm}$ (FNCL, Worker Gage, Esteio, Brazil). The root anatomy and foraminal patency were confirmed, so that specimens with two canals, extensive caries, or without foraminal patency were substituted. The working length (WL) of the root canals was determined by inserting manual K-files (Dentsply-Sirona, Ballaigues, Switzerland) until the tip was visible through the apical foramen (AF), subtracting $1 \mathrm{~mm}$, through a clinical microscope (DF Vasconcellos, São Paulo, SP, Brazil) at 25× magnification. Still under magnification, the AFs were standardized with size 20 K-file $(200 \mu \mathrm{m})$; to enable reflux action during irrigation, the AFs were covered with utility wax (Lysanda Dental Products, São Paulo, SP, Brazil).

Subsequently, the specimens were randomly divided into two groups according to widening (size 25, 0.08 taper or size 40, 0.08 taper). Before beginning with instrumentation, all the specimens were irrigated with $2 \mathrm{~mL}$ of $2.5 \% \mathrm{NaOCl}$. The canals were prepared with WaveOne Primary (size 25, 0.08 taper) or Large (size 40, 0.08 taper) (Dentsply-Sirona) instruments, driven by an electric motor (VDW Silver; VDW GmbH, Munich, 
Germany) in the "WaveOne" program. The instrumentation procedures were performed in slow back-and-forth cycles of movement. Between every cycle, new irrigation was performed with $2 \mathrm{~mL}$ of $2.5 \% \mathrm{NaOCl}$. After every sequence, the instrument spirals were cleaned with gauze and recapitulation of the root real length with a size 20 $\mathrm{K}$-file was performed. All the irrigation steps, irrespective of the solution used, were performed with the aid of a Luer-type disposable syringe (Becton Dickinson, Juiz de Fora, MG, Brazil) adapted to the needle specifically for irrigation (NaviTip 29G; Ultradent, South Jordan, UTAH, USA) with penetration limiter calibrated to restrict penetration depth to $12.0 \mathrm{~mm}$.

Irrespective of the group of which the specimens formed part, a single, previously trained operator, using the crown down technique, performed RCP of the cervical, middle, and apical thirds.

After RCP, the specimens were randomly distributed into four experimental subgroups $(n=10)$. The experimental groups were formed according to the preparation of the foraminal diameter and agitation/activation of the chelating agent 17\% EDTA (Biodinâmica Química e Farmacêutica Ltda., Ibiporã, PR, Brazil). The experimental subgroups were as follows: ECROT; ECREC, PUI, and EDTA solely. Two control groups were prepared $(n=5)$, both with widening up to size $40,0.08$ taper. In the positive control group $(\mathrm{C}+)$ the teeth were prepared and instrument in a similar manner to that described for the size 40 experimental groups; however, they were also submitted to a bath in an ultrasonic tub (size 1210; Brason, Connecticut, USA) for 5 minutes with $2.5 \% \mathrm{NaOCl}$ and 1 minute with $17 \%$ EDTA, whereas, the specimens in the negative control group (C-) were also instrumented with size 40 , but they were irrigated with a $0.9 \%$ sodium chloride $(\mathrm{NaCl})$ solution (Farmence, Barbalha, CE, Brazil) instead of NaOCl; these specimens did not undergo any type of bath or agitation, and did not receive any chelating agent.

The agitation/activation protocols were used as follows:

\section{Ethylenediaminetetraacetic Acid}

Irrigation with $1.0 \mathrm{~mL}$ of chelating agent for 1 minute was used. This was repeated another 2 times, totaling 3 minute and $3.0 \mathrm{~mL}$ of EDTA.

\section{Easy Clean-Continuous Rotation}

Agitation was performed with size 25, 0.04 taper EC driven by an electric motor in continuous rotation to the right at a speed of 1000 rotations per minute (RPM) (VDW Silver). Irrigations were performed with $1.0 \mathrm{~mL}$ of chelating agent for 1 minute. During this 1 minute, 30 seconds agitation was performed with the EC tip in continuous rotation; this procedure was repeated another 2 times, resulting in a total time of 3 minute and 3 mL EDTA.

\section{Easy Clean-Reciprocating}

Agitation was performed with EC driven by an Endo Easy SI motor (Easy Dental Equipment) in alternate reciprocal motion (ARM function). Irrigations were performed with $1.0 \mathrm{~mL}$ of chelating agent for 1 minute. During this 1 minute, 30 seconds agitation was performed with the EC in ARM; this procedure was repeated another 2 times, resulting in a total time of 3 minutes and $3 \mathrm{~mL}$ EDTA.

\section{Passive Ultrasonic Irrigation}

Agitation was performed with insert E1 (Irrisonic; Helse Ultrassonics, Santa Rosa de Veterbo, SP, Brazil) activated in ultrasound EMS PIEZON (PM200; EMS, São Bernardo do Campo, SP, Brazil) at power $3(30 \mathrm{kHz})$. Special attention was paid to maintaining the tip centralized in the root canal, so that it would not touch the dentin walls. The vibration was used in the direction of the walls that would be analyzed (mesiodistal). Irrigations were performed with $1 \mathrm{~mL}$ of chelating agent for 1 minute. During this 1 minute, 30 seconds of ultrasonic agitation was performed; this procedure was repeated another 2 times, resulting in a total time of 3 minutes and 3 mL EDTA.

On conclusion of the RCP and EDTA agitation/activation procedures, irrespective of the group of which they formed part, the specimens received final irrigation with $5 \mathrm{~mL}$ of $0.9 \% \mathrm{NaCl}$ and were thereafter dried with absorbent paper cones (Endopoints, Paraíba do Sul, RJ, Brazil). Longitudinal grooves were made on the vestibular and lingual surfaces of the roots close up to the root canal, however, without attaining it. With guidance provided by the wear and with the help of a chisel, the teeth were cleaved longitudinally, thus obtaining two hemi-surfaces. Measurements of 2, 6, and $10 \mathrm{~mm} \mathrm{WL}$ were determined as areas of each third in each hemi surface. The portions produced were mounted on stubs and analyzed by variable pressure SEM (Aspex Express; FEI Europe, Eindhoven, Holland) at voltage of $15-20 \mathrm{kV}$ and at $750 \times$ magnification. Images were captured, recorded, and analyzed by two duly calibrated examiners; the image capture and classification procedures were performed in a double-blind manner. In case of disagreement between the examiners, a third examiner was called. For later determination of intraexaminer agreement, some images were randomly selected and duplicated.

To evaluate cleaning, scores were attributed to the images according to parameters adapted from Arslan et $\mathrm{al}^{17}: 0=$ surface free of debris and residual layer, in addition to complete exposure of dentinal tubule openings; 1 = surface presented residual layer covering only tubule 
openings, making it possible to observe their outline in the largest wall evaluated; 2 = surface with thin residual layer covering the dentinal tubules, making it possible to observe them in small areas only; 3 = surface completely covered by debris, making it impossible to observe any areas of dentinal tubule openings.

After obtaining the scores attributed by the evaluators, the Kappa inter- and intraexaminer values were determined, with these values being higher than $83 \%$ in all the evaluations. Subsequently, each third was analyzed by the Kruskal-Wallis and Student-Newman-Keuls individual comparison tests, both with $\mathrm{p}<0.05$. To determine possible differences in cleaning among the thirds relative to widening, the Friedman test was applied $(p<0.05)$.

\section{RESULTS}

The median, minimum, and maximum values, and the mean postscores attributed to the groups in the cervical, middle, and apical thirds of the root canals at different apical enlargements are presented in Tables 1 to 3 respectively. Figures 1 to 3 illustrate the cleanness provided by the experimental groups at each root canal third.

In the cervical and middle thirds, no statistically significant differences were observed when each of the experimental groups was compared relative to the different widening values (size 25, 0.08 taper and size 40, 0.08 taper) $(p>0.05)$. In the cervical third, considering comparisons of the experimental groups with $\mathrm{C}_{+}$, significant differences were observed between $\mathrm{C}+$ and the experimental groups EDTA, ECREC, and PUI relative to widening up to size 25, 0.08 taper, and EDTA at the widening up to size $40,0.08$ taper $(\mathrm{p}<0.05)$.

In the evaluation of the middle third, considering widening up to size $25,0.08$ taper, statistically significant difference were observed between the EDTA and PUI groups and $C+(p<0.05)$, which did not occur in the widening up to size $40,0.08$ taper in which no significant

Table 1: Median, minimum and maximum values, and mean post of the cleaning scores attributed to the groups in the cervical third

\begin{tabular}{|c|c|c|c|c|c|c|c|c|}
\hline \multirow[b]{2}{*}{ Group } & \multicolumn{4}{|c|}{$R 25$} & \multicolumn{4}{|c|}{$R 40$} \\
\hline & Median & Min. & Max. & Mean post & Median & Min. & Max. & Mean post \\
\hline EDTA & 1 & 0 & 1 & $43.75^{\mathrm{b}, \mathrm{A}}$ & 1 & 0 & 2 & $47.05^{\mathrm{b}, \mathrm{A}}$ \\
\hline ECREC & 1 & 0 & 2 & $49.5^{\mathrm{b}, \mathrm{A}}$ & 1 & 0 & 3 & $36.33^{\mathrm{ab}, \mathrm{A}}$ \\
\hline ECROT & 0 & 0 & 2 & $31.83^{\mathrm{ab}, \mathrm{A}}$ & 0.5 & 0 & 2 & $34.06^{\mathrm{ab}, \mathrm{A}}$ \\
\hline PUI & 1 & 0 & 2 & $45.15^{\mathrm{b}, \mathrm{A}}$ & 1 & 0 & 1 & $32.89^{\mathrm{ab}, \mathrm{A}}$ \\
\hline $\mathrm{C}+$ & 0 & 0 & 0 & $14^{\mathrm{a}}$ & 0 & 0 & 0 & $14^{a}$ \\
\hline C- & 3 & 3 & 3 & $79^{c}$ & 3 & 3 & 3 & $79^{c}$ \\
\hline
\end{tabular}

$\mathrm{a}, \mathrm{b}, \mathrm{c}$ Different lowercase superscript letters represent significant differences between groups at each apical enlargement according to the Kruskal-Wallis and Student-Newman-Keuls tests $(p<0.05) ;{ }^{A}, \mathrm{~B}$ Different uppercase superscript letters represent significant differences between each method of agitation in the different apical enlargements according to the Kruskal-Wallis and Friedman tests $(p<0.05)$

Table 2: Median, minimum and maximum values, and mean post of the cleaning scores attributed to the groups in the medium third

\begin{tabular}{|c|c|c|c|c|c|c|c|c|}
\hline \multirow[b]{2}{*}{ Group } & \multicolumn{4}{|c|}{$R 25$} & \multicolumn{4}{|c|}{$R 40$} \\
\hline & Median & Min. & Max. & Mean post & Median & Min. & Max. & Mean post \\
\hline EDTA & 1 & 0 & 3 & $44.69^{\mathrm{b}, \mathrm{A}}$ & 1 & 0 & 2 & $39.85^{\mathrm{a}, \mathrm{A}}$ \\
\hline ECREC & 1 & 0 & 2 & $42.85^{\mathrm{ab}, \mathrm{A}}$ & 1 & 0 & 3 & $37.83^{\mathrm{a}, \mathrm{A}}$ \\
\hline ECROT & 1 & 0 & 2 & $40.67^{\mathrm{a}, \mathrm{A}}$ & 1 & 0 & 2 & $36.63^{a, A}$ \\
\hline PUI & 1 & 0 & 2 & $48.85^{\mathrm{b}, \mathrm{A}}$ & 1 & 0 & 1 & $33^{\mathrm{a}, \mathrm{A}}$ \\
\hline $\mathrm{C}+$ & 0 & 0 & 1 & $16.38^{a}$ & 0 & 0 & 1 & $16.38^{a}$ \\
\hline C- & 2.5 & 2 & 3 & $74.5^{\mathrm{b}}$ & 2.5 & 2 & 3 & $74.5^{\mathrm{b}}$ \\
\hline
\end{tabular}

${ }_{\mathrm{a}, \mathrm{b}}$ Different lowercase superscript letters represent significant differences between groups at each apical enlargement according to the Kruskal-Wallis and Student-Newman-Keuls tests $(p<0.05) ;{ }^{A, B}$ Different uppercase superscript letters represent significant differences between each method of agitation in the different apical enlargements according to the Kruskal-Wallis and Friedman tests $(p<0.05)$

Table 3: Median, minimum and maximum values, and mean post of the cleaning scores attributed to the groups in the apical third

\begin{tabular}{|c|c|c|c|c|c|c|c|c|}
\hline \multirow[b]{2}{*}{ Group } & \multicolumn{4}{|c|}{$R 25$} & \multicolumn{4}{|c|}{$R 40$} \\
\hline & Median & Min. & Max. & Mean post & Median & Min. & Max. & Mean post \\
\hline EDTA & 2 & 1 & 3 & $52.94^{\mathrm{bc}, \mathrm{A}}$ & 2 & 1 & 3 & $49.05^{\mathrm{cd}, \mathrm{A}}$ \\
\hline ECREC & 2 & 1 & 3 & $49.05^{\mathrm{bc}, \mathrm{A}}$ & 1 & 0 & 3 & $33.95^{\mathrm{bc}, \mathrm{A}}$ \\
\hline ECROT & 2 & 2 & 3 & $47.72^{\mathrm{bc}, \mathrm{B}}$ & 1 & 1 & 2 & $25.19^{\mathrm{ab}, \mathrm{A}}$ \\
\hline PUI & 2 & 0 & 3 & $42.70^{\mathrm{b}, \mathrm{B}}$ & 1 & 0 & 1 & $18.11^{\mathrm{ab}, \mathrm{A}}$ \\
\hline $\mathrm{C}+$ & 0 & 0 & 0 & $16.38^{a}$ & 0 & 0 & 0 & $16.38^{a}$ \\
\hline C- & 3 & 3 & 3 & $74.5^{\mathrm{d}}$ & 3 & 3 & 3 & $74.5^{d}$ \\
\hline
\end{tabular}

$\overline{a, b, c, d}$ Different lowercase superscript letters represent significant differences between groups at each apical enlargement according to the Kruskal-Wallis and Student-Newman-Keuls tests $(p<0.05)$; ${ }^{A, B}$ Different uppercase superscript letters represent significant differences between each method of agitation in the different apical enlargements according to the Kruskal-Wallis and Friedman tests $(p<0.05)$ 


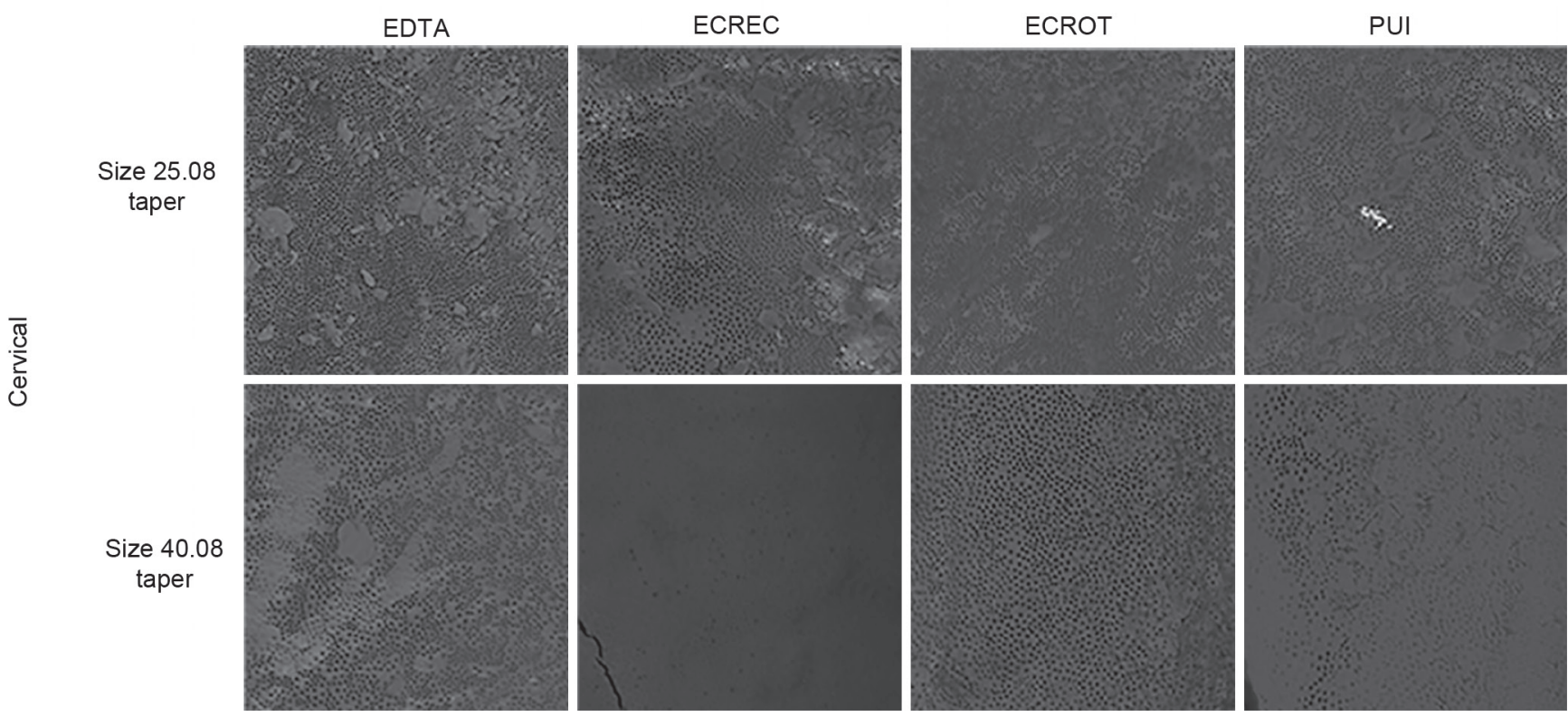

Fig. 1: Representative SEM photomicrographs $(750 \times)$ of the cleanness provided by the experimental groups in both apical enlargements tested at the cervical root canal third. The major part of dentin uncovered by smear layer, and opened dentin tubules

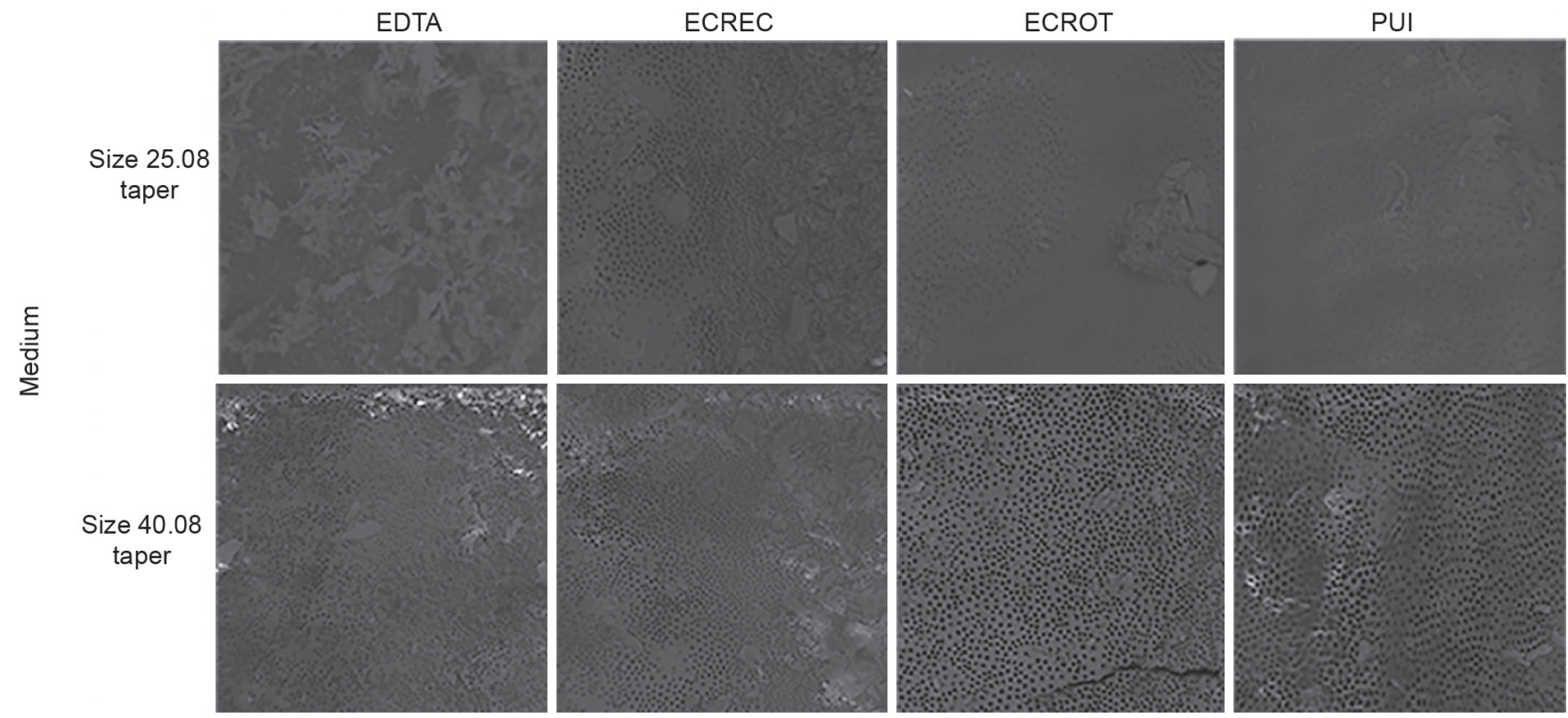

Fig. 2: Representative SEM photomicrographs (750x) of the cleanness provided by the experimental groups in both apical enlargements tested at the medium root canal third. The major part of dentin uncovered by smear layer, and opened dentin tubules

differences were identified between the experimental groups and $C+(p>0.05)$.

In relation to the apical third, differently from the other thirds, significant differences were observed in some of the agitation methods when considering the two widening values, with ECROT and PUI having increased their cleaning capacity in the larger widening values size $40 / 0.08$ taper $(\mathrm{p}<0.05)$. When analyzing the agitation methods in each of the widening tested, no significant differences were observed in the widening up to size 25, 0.08 taper ( $p>0.05)$; however, all the experimental groups showed values lower than those of $C+(p<0.05)$. In this third, considering the data relative to the specimens with widening up to size 40, 0.08 taper, significant differences were observed between the activation methods and the use of EDTA solely $(\mathrm{p}<0.05)$, which presented results similar to those of $\mathrm{C}-$.

Not considering the groups individually, and statistically evaluating the overall data, it was observed that the widening (size 25, 0.08 taper vs size 40, 0.08 taper) influenced the results, by producing significant difference in favor of greater widening both in the overall evaluation $(p<0.05)$ and in the evaluation of the apical third $(\mathrm{p}<0.05)$. Furthermore, considering the widening, 


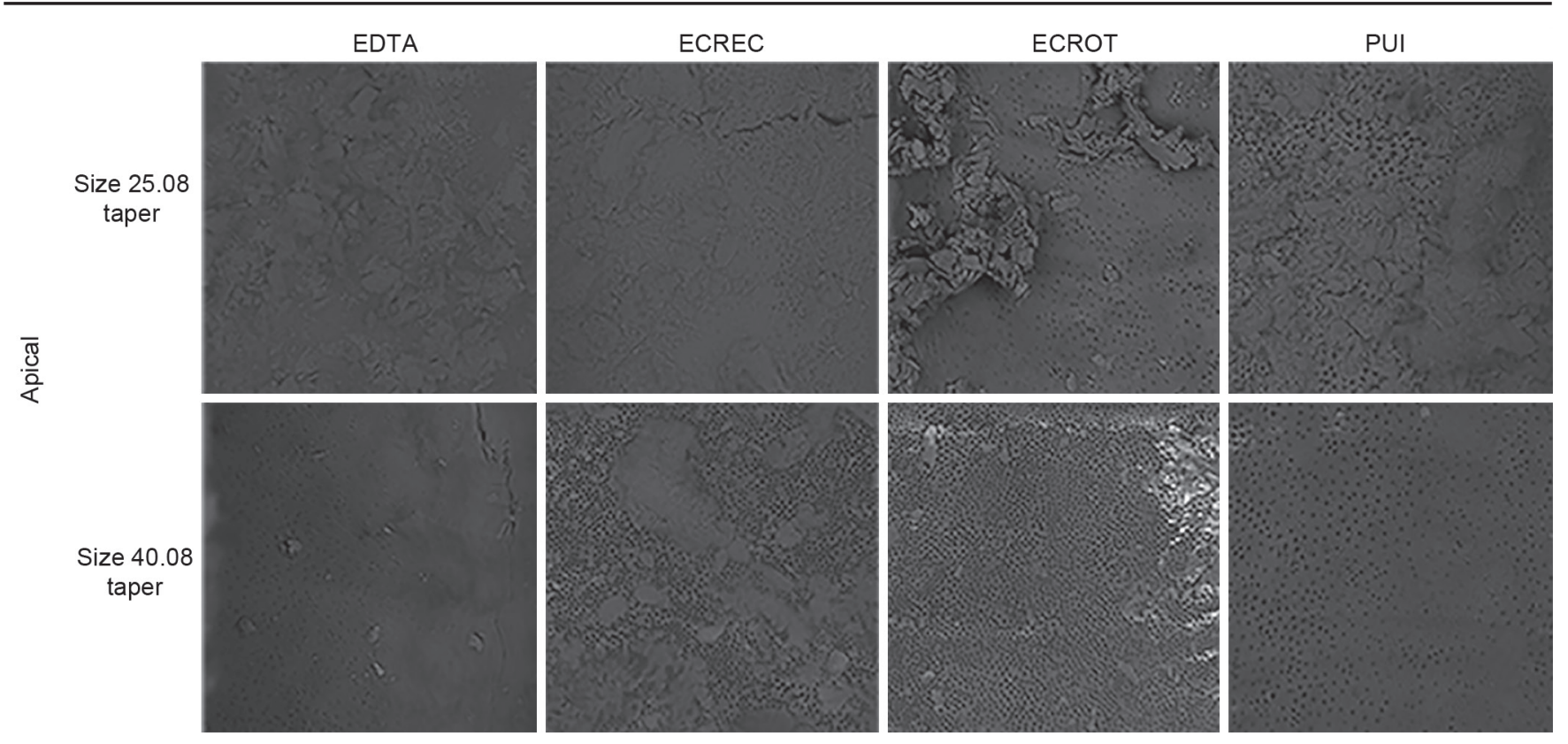

Fig. 3: Representative SEM photomicrographs $(750 \times)$ of the cleanness provided by the experimental groups in both apical enlargements tested along the root canal thirds. It could be noted that the cleaning efficacy of agitation protocols were increased when the apical enlargement was bigger

no differences were found among the thirds (cervical vs middle $v s$ apical) in the specimens widened up to size 40, 0.08 taper; however, these differences were observed in the enlargement up to size 25, 0.08 taper, with the apical third being statistically inferior to the other thirds $(\mathrm{p}<0.05)$.

\section{DISCUSSION}

The present study evaluated the influence of widening the $\mathrm{RCP}$ on cleaning and debris removal provided by EDTA and three protocols for agitating it. The null hypothesis was rejected because the higher widening value favored better cleaning provided by the agitation protocols.

The EDTA solution was used in this study to have its proven action in the aid of the removal of the smear layer. ${ }^{2,4,5}$ Additionally, Herrera et $\mathrm{al}^{18}$ recently pointed out that the ultrasonic activation of EDTA was effective in further reducing endotoxin levels in the root canals of teeth with pulp necrosis and apical periodontitis.

The unirradicular mandibular premolars had their real length and AFs standardized before being used, thus guaranteeing the homogeneity between both the groups (size 25, 0.08 taper vs size 40, 0.08 taper) and subgroups. Details, such as foraminal and root length standardization, together with obliteration of the AFs and establishment of a standard depth for irrigation demonstrate the care taken to exclude possible methodological biases and the endeavor to simulate the conditions of clinical use as far as possible. ${ }^{19,20}$ In the same direction, the authors opted for the use of a single mechanized instrumentation system for both widening procedures, in this case WaveOne. This not only allowed standardization relative to kinematics and cross-section, but has been pointed out as being one of the factors that led to root canal walls remaining dirtier at the end of canal preparation. ${ }^{21}$ With reference to the positive and negative controls, the canals were widened up to size 40, 0.08 taper in both. For C+, the authors considered that the higher widening values would favor the action of the substances during agitation in the ultrasonic bath, making possible a better cleaning of the walls; for $\mathrm{C}_{-}$, the authors considered that the higher widening values without the use of any smear layer removal protocol would provide really dirty root canal walls. These predictions appear to have been proved considering the scores received by these groups.

Some studies have demonstrated that the use of a chelating solution alone has limited capacity for removing the smear layer and debris present in the canals after RCP. ${ }^{15,22,23}$ These findings partly corroborated those of the present study; however, the results here found pointed out significant advantage of the use of activation methods, more specifically in cleaning the apical thirds and in more widened canals. In the case of the less widened canals, no cleaning method, whether the use of EDTA solely, or by means of its activation, was able to produce results similar to those offered by $\mathrm{C}+$.

Taking into consideration the results, greater enlargements appeared to have a positive influence on the cleaning capacity of EDTA, irrespective of the protocol for using it, corroborating the study of Rodrigues et al ${ }^{11}$ that showed that the higher widening values promoted greater disinfection of the canals in cases of apical periodontitis. Cleaner canals were observed with higher frequency in both the overall evaluation and that of the apical third, irrespective of the protocol used, and when 
widening of up to size 40, 0.08 taper was performed. This finding reinforces other studies that have recommended widening of the preparation with instruments size 40 to remove a larger amount of debris and achieve improved cleaning in the apical third. ${ }^{24,25}$ Authors suggest that the proximity to the canal walls could reduce the ultrasonic action of the insert, restricting the action of cavitation and shock waves of the irrigant solution against the canal walls, preventing their more efficient cleaning. ${ }^{26,27}$

Considering the EDTA agitation protocols evaluated, in general, no significant differences were found among them in both the cervical and middle thirds, irrespective of the widening performed. The results suggest that widening did not provide the liquids with specific physical actions, such as those provided by PUI; the mechanical agitation generated by swirling the chelating solution by means of EC, either by rotary or reciprocating kinematics, was capable of producing results similar to this. However, this behavior was not repeated when observing the cleaning provided at apical level with the higher enlargement, a condition in which the PUI and ECROT protocols offered the best results, as they were the only ones to offer values statistically similar to those of $\mathrm{C}+$. These findings reinforce the importance of the free action of the ultrasonic insert. Studies have pointed out that the amplitude of insert displacement in the canal was capable of promoting an intermittent flow, forming bubbles that are driven against the canal walls under pressure, generating cavitation and shock waves, resulting in displacement of the debris. ${ }^{13,20,26,28}$ As far as EC is concerned, in a proportional manner, the authors believe that as it refers to a plastic instrument size 25, 0.04 taper, its action in continuous rotation at high speed in wider regions would reduce locking of its tip and provide greater swirling action, thereby favoring its cleaning efficiency.

Simplification of instrumentation has led to agility in RCS preparation, in detriment to its cleaning. The findings of this study reinforce the need for clinical use of additional methods to complement cleaning. Therefore, it is important for professionals to have knowledge and command of these protocols to obtain more satisfactory results.

\section{CONCLUSION}

Under the conditions of this study, the authors could conclude that higher widening values of RCPs provide significant improvement in the action of the RCS cleaning protocols. Furthermore, EDTA agitation protocols are important for obtaining improved results at apical level, with PUI and ECROT offering the best results.

\section{CLINICAL SIGNIFICANCE}

The findings of this study reinforce the need for clinical use of additional methods to complement cleaning. Therefore, it is important for professionals to have knowledge and command of these protocols to obtain more satisfactory results.

\section{REFERENCES}

1. Versiani MA, Pecora JD, de Sousa-Neto MD. Flat-oval root canal preparation with self-adjusting file instrument: a micro-computed tomography study. J Endod 2011 Jul;37(7): 1002-1007.

2. Stojicic S, Zivkovic S, Qian W, Zhang H, Haapasalo M. Tissue dissolution by sodium hypochlrorite: effect of concentration, temperature, agitation and surfactant. J Endod 2010 Sep;36(9):1558-1562.

3. Ozdemir HO, Buzoglu HD, Calt S, Cehreli ZC, Varol E, Temel A. Chemical and ultramorphologic effects of ethylenediaminetetraacetic acid and sodium hypochlorite in young and old root canal dentin. J Endod 2012 Feb;38(2):204-208.

4. Machado R, Garcia LD, da Silva Neto UX, Cruz Filho AM, Silva RG, Vansan LP. Evaluation of 17\% EDTA and 10\% citric acid in smear layer removal and tubular dentin sealer penetration. Microsc Res Tech 2018 Mar;81(3):275-282.

5. Arslan H, Ayrancı LB, Karatas E, Topçuoğlu HS, Yavuz MS, Kesim B. Effect of agitation of EDTA with 808-nanometer diode laser on removal of smear layer. J Endod 2013 Dec;39(12): 1589-1592.

6. Darcey J, Jawad S, Taylor C, Roudsari RV, Hunter M. Modern endodontic principles part 4: irrigation. Dent Update 2016 Jan-Feb;43(1):20-22, 25-26, 28-30 passim.

7. VersianiMA, LeoniGB,Steier L, De-DeusG, TassaniS, Pécora JD, de Sousa-Neto MD. Micro-computed tomography study of oval-shaped canals prepared with the self-adjusting file, Reciproc, WaveOne, and ProTaper universal systems. J Endod 2013 Aug;39(8):1060-1066.

8. Bürklein S, Benten S, Schäfer E. Quantitative evaluation of apically extruded debris with different single-file systems: Reciproc, F360 and OneShape versus Mtwo. Int Endod J 2014 May;47(5):405-409.

9. Arnold M, Ricucci D, Siqueira JF Jr. Infection in a complex network of apical ramifications as the cause of persistent apical periodontitis: a case report. J Endod 2013 Sep;39(9): 1179-1184.

10. Agarwal A, Deore RB, Rudagi K, Nanda Z, Baig MO, Fareez MA. Evaluation of apical vapor lock formation and comparative evaluation of its elimination using three different techniques: an in vitro study. J Contemp Dent Pract 2017 Sep;18(9):790-794.

11. Rodrigues RC, Zandi $H$, Kristoffersen AK, Enersen $M$, Mdala I, Orstavik D, Siqueira JF Jr. Influence of the apical preparation size and the irrigant type on bacterial reduction in root canal-treated teeth with apical periodontitis. J Endod 2017 Jul;43(7):1058-1063.

12. Kuah HG, Lui JN, Tseng PS, Chen NN. The effect of EDTA with and without ultrasonics on removal of the smear layer. J Endod 2009 Mar;35(3):393-396.

13. da Costa Lima GA, Aguiar CM, Câmara AC, Alves LC, Dos Santos FA, do Nascimento AE. Comparison of smear layer removal using the Nd:YAG laser, ultrasound, ProTaper 
universal system and canal brush methods: an in vitro study. J Endod 2015 Mar;41(3):400-404.

14. Kato AS, Cunha RS, da Silva Bueno CE, Pelegrine RA, Fontana CE, de Martin AS. Investigation of the efficacy of passive ultrasonic irrigation versus irrigation with reciprocating activation: an environmental scanning microscopic study. J Endod 2016 Apr;42(4):659-663.

15. Duque JA, Duarte MA, Canali LC, Zacan RF, Vivan RR, Bernardes RA, Bramante CM. Comparative effectiveness of new mechanical irrigant agitating devices for debris removal from the canal and isthmus of mesial roots of mandibular molars. J Endod 2017 Feb;43(2):326-331.

16. Ahmed HM, Versiani MA, De-Deus G, Dummer PM. A new system for classifying root and root canal morphology. Int Endod J 2017 Aug;50(8):761-770.

17. Arslan D, Guneser MB, Dincer AN, Kustarci A, Er K, Siso $\mathrm{SH}$. Comparison of smear layer removal ability of Qmix with different activation techniques. J Endod 2016 Aug;42(8):1279-1285.

18. Herrera DR, Martinho FC, de-Jesus-Soares A, Zaia AA, Ferraz CC, Almeida JF, Gomes BP. Clinical efficacy of EDTA ultrasonic activation in the reduction of endotoxins and cultivable bacteria. Int Endod J 2017 Oct;50(10):933-940.

19. Thomas AR, Velmurugan N, Smita S, Jothilatha S. Comparative evaluation of canal isthmus debridement efficacy of modified EndoVac technique with different irrigation systems. J Endod 2014 Oct;40(10):1676-1680.

20. Freire LG, Iglecias EF, Cunha RS, Dos Santos M, Gavini G. Micro-computed tomographic evaluation of hard tissue debris removal after different irrigation methods and its influence on the filling of curved canals. J Endod 2015 Oct;41(10): $1660-1666$
21. Dietrich MA, Kirkpatrick TC, Yaccino JM. In vitro canal and isthmus debris removal of the self-adjusting file, $\mathrm{K} 3$, and WaveOne files in the mesial root of human mandibular molars. J Endod 2012 Aug;38(8):1140-1144.

22. Koçak S, Bağc1 N, Çiçek E, Türker SA, Can Sağlam B, Koçak MM. Influence of passive ultrasonic irrigation on the efficiency of various irrigation solutions in removing smear layer: a scanning electron microscope study. Microsc Res Tech 2017 May;80(5):537-542.

23. Tanomaru-Filho M, Miano LM, Chávez-Andrade GM, Torres FF, Leonardo Rde T, Guerreiro-Tanomaru JM. Cleaning of root canal system by different irrigation methods. J Contemp Dent Pract 2015 Nov;16(11):859-863.

24. Usman N, Baumgartner JC, Marshall JG. Influence of instrument size on root canal debridement. J Endod 2004 Feb;30(2):110-112.

25. De-Deus G, Belladonna FG, Silva EJ, Marins JR, Souza EM, Perez R, Lopes RT, Versiani MA, Paciornik S, Neves Ade A. Micro-CT evaluation of non-instrumented canal areas with different enlargements performed by NiTi systems. Braz Dent J 2015 Nov-Dec;26(6):624-629.

26. van der Sluis LW, Versluis M, Wu MK, Wesselink PR. Passive ultrasonic irrigation of the root canal: a review of the literature. Int Endod J 2007 Jun;40(6):415-426.

27. Cavenago BC, Ordinola-Zapata R, Duarte MA, del CarpioPerochena AE, Villas-Bôas MH, Marciano MA, Bramante CM, Moraes IG. Efficacy of xylene and passive ultrasonic irrigation on remaining root filling material during retreatment of anatomically complex teeth. Int Endod J 2014 Nov;47(11):1078-1083.

28. Plotino G, Pameijer CH, Grande NM, Somma F. Ultrasonics in endodontics: a review of the literature. J Endod $2007 \mathrm{Feb} ; 33(2)$ : 81-95. 